\title{
PROPOSTA DE GEL HIGIENIZANTE BUCAL PARA CÃES À BASE DE FITOTERÁPICOS COM POLÍMERO LIVRE DE BENZENO
}

\section{PORPOUSAL OF MOUTH HYGIENIC GEL FOR DOGS BASED ON PHYTOTHERAPY WITH BENZENE FREE POLYMER}

\author{
Bruna dos Santos SANSÃO1; Karina Sayuri KIMURA'; Lígia Moura BURCI²; Marilis \\ Dallarmi MIGUEL³; Obdulio Gomes MIGUEL³; Josiane de Fatima Gaspari DIAS³; \\ Pedro ZANIN ${ }^{4}$; Sandra Maria Warumby ZANIN ${ }^{3}$
}

1 - Acadêmica do curso de Farmácia na Universidade Federal do Paraná

2 - Doutoranda em Ciências Farmacêuticas na Universidade Federal do Paraná

3 - Professor do curso de Farmácia e da Pós-Graduação em Ciências Farmacêuticas na Universidade Federal do Paraná

4 - Engenheiro Químico

Autor para correspondência: ligia.burci@gmail.com

\section{RESUMO:}

O presente trabalho teve como objetivo realizar o estudo de possíveis bases para formulação de gel higienizante bucal de cães, prevenindo assim periodontite, gengivite e outros possíveis problemas bucais. A metodologia do trabalho foi por meio de revisão bibliográfica para verificar quais os principais tipos de Carbopol® utilizados no desenvolvimento de géis para a formulação, principais características físico-químicas do Carbopo|® presença ou não de resíduos de benzeno na fabricação dos polímeros, preocupando-se e verificando os principais problemas de saúde do uso de produtos com presença de benzeno, independentemente da quantidade. Verificou-se os principais produtos em formulações de géis para limpeza, e por fim, após a análise dos dados obtidos realizou-se uma sugestão de uma formulação de gel para limpeza bucal de cães, com eficácia e sem riscos à saúde com o uso prolongado.

Palavras-chave: benzeno, gel, formulação, fitoterápico.

\section{ABSTRACT:}

The present work objective of studying the possible bases for the formulation of oral hygienizing gel for dogs, thus preventing periodontitis, gingivitis and other possible oral problems. The methodology of the work was by means of a bibliographical review to verify the main types of Carbopol ${ }^{\circledR}$ used in the development of gels for the formulation, the main physical-chemical characteristics of Carbopol ${ }^{\circledR}$ presence or not of benzene residues in the manufacture of the polymers, and check the main health problems of the use of benzene products, regardless of the quantity. The main products were verified in cleaning gels formulations. Finally, with the analysis of the data obtained, a suggestion was made of a possible formulation of oral cleaning gel for dogs, with effectiveness and without health risks with prolonged use.

Keywords: benzene, gel, formulation, phytotherapy. 


\section{INTRODUÇÃO}

A odontologia veterinária tem se desenvolvido muito no Brasil nos últimos anos, pela própria importância e gravidade que as doenças odontológicas veterinárias podem causar aos cães, muitas vezes interferindo na qualidade de vida do animal (DEBOWES et al., 1996). Aproximadamente $85 \%$ dos cães com mais de 4 anos de vida que, frequentam clínicas veterinárias, são diagnosticados com doença periodontal (COLMERY, FROST, 1986; LYON, 1991).

O principal fator que desencadeia doença periodontal é a placa bacteriana, caracterizada por um biofilme bacteriano aderido à superfície dos dentes do animal, proveniente de restos alimentares, restos celulares e bactérias, em sua maioria aeróbias (DUPONT, 1997). A placa bacteriana também causa uma resposta inflamatória levando à gengivite, a qual se não for tratada e controlada poderá evoluir para a periodontite (PENMAN, HARVEY, 1992; BROOK, NIEMIEC, 2008). A doença periodontal em cães pode proporcionar problemas sistêmicos, causados pelo alto nível de toxinas bacterianas na cavidade bucal, pois as mesmas podem penetrar na corrente sanguínea, acumulando-se em órgãos como rins, fígado e coração provocando graves doenças no animal (PENMAN, 1990; DEBOWES et al., 1996).

Os principais sintomas clínicos da doença periodontal são halitose intensa, sangramento oral, mobilidade dental, gengivite e salivação espessa (GIOSO, 2003). Diante da gravidade da doença periodontal, suas possíveis complicações e consequências, tornase importante a conscientização da prática da escovação do dente do animal, que atua destruindo o biofilme de bactérias, e reduzindo a placa bacteriana em quase 95\% (LIMA et al., 2004).

Segundo alguns autores, para que o cão tenha a gengiva saudável são necessárias três escovações por semana, essa prática reduz em até $90 \%$ a ocorrência de periodontite, pelo controle da placa bacteriana, contudo, apenas menos que $10 \%$ dos tutores de cães tem o hábito da higienização bucal do animal (MILLER, HARVEY, 1994; DUPONT, 1998).

Atualmente, a substância mais eficaz para realizar a limpeza oral do cão é o antisséptico com Clorexidina em solução de 0,12\% a 0,50\%. A Clorexidina apresenta-se muito eficiente no controle das placas bacterianas, no entanto causa manchas escuras nos dentes com o uso prolongado, além do seu sabor amargo causar dificuldades de aceitação pelo animal (GIOSO, 2003).

Devido à importância do cuidado da saúde bucal do animal, e à crescente demanda 
que esse material apresenta atualmente, realizou-se esse estudo com o objetivo de elencar os diferentes tipos de Carbopolß existentes comercialmente e sugerir uma fórmula veterinária de gel higienizante bucal para cães sem resíduos de benzeno.

\section{METODOLOGIA}

Trabalho exploratório que objetivou elencar as formulações para gel dental existentes no mercado atualmente. Para isso foi realizada uma revisão em bulas, fichas técnicas e em sites de busca no Brasil, para essa verificação. Foram incluídos na pesquisa materiais a base de benzeno, e aqueles livres do benzeno, realizando-se uma comparação de ambos. Além da proposta final de um gel para higienização contendo fitoterápicos e livre do benzeno.

\section{RESULTADOS E DISCUSSÃO}

A forma farmacêutica gel consiste em um semissólido com pequenas partículas inorgânicas, com a adição de um agente gelificante, conferindo viscosidade ao sistema, com dimensões entre $1 \mathrm{~nm}$ e $1 \mu \mathrm{m}$, distribuídas no sistema uniformemente (FNFB, 2012). Segundo o Formulário Nacional da Farmacopéia Brasileira, gel hidrofóbico ou também chamado de gel de fase dupla, normalmente consiste em parafina líquida com polietileno ou óleos gordurosos, já o gel hidrofílico é resultado da preparação de agente gelificante, classificados também em gel de fase única (FNFB, 2012).

\subsection{Benzeno}

É uma substância química tóxica que causa sérios problemas de saúde quando inalado, quando em contato com a pele ou ingerido o produto pode levar ao desenvolvimento de câncer. Comumente é utilizado como matéria-prima na indústria química para fabricação de tintas, borrachas, detergentes, medicamentos, refino de petróleos, gasolina sendo encontrado em resíduos da produção de alguns produtos químicos ou matéria-prima (GUIMARÃES et al., 2003).

Um dos problemas do benzeno é acumulado nos tecidos que apresentam alto teor de gordura, sendo de 10 a 50\%, dependendo da porcentagem de gordura que o indivíduo apresenta em seu organismo. A eliminação do produto em sua maioria ocorre a partir do 
fígado e medula óssea (ATSDR, 2007). O limite de exposição, segundo a Occupation Safety and Health Administration deve ser de 1 ppm, ou se for uma exposição de curta duração, pode chegar a 5 ppm. No entanto, segundo a legislação brasileira, não há limite seguro para a exposição ao benzeno, pois não existe definição sobre dose-dependência para que se tenha ação cancerígena, mesmo que seja em doses e concentrações baixas (BRASIL, 2004).

A forma mais segura de prevenção aos problemas causados pelo benzeno é evitar a exposição à substância, e quando possível substituir o benzeno por outros produtos. Segundo estudos, a exposição do hidrocarboneto pode causar doenças graves, mesmo que o contato seja de curta duração ou em poucas vezes por semana ou meses (FUNDACENTRO, 2012).

\subsection{Carbopol®}

Em formulações específicas, utiliza-se o Carbopol® para a formulação de gel. O Carbopolß é um polímero hidrossolúvel, de alto peso molecular, derivado do ácido carboxivinílico. Carbopo|® é o nome comercial do polímero produzido a partir de carbômeros, sendo utilizado como matéria prima na produção de géis, cosméticos, com a função de estabilizar emulsões e aumentar a viscosidade de soluções (HOSMANI, 2010).

Existem vários tipos de Carbopo|ß, que são distintos por apresentarem algumas diferenças físico-químicas, e são usados diversos números para cada tipo de Carbopo|ß. Polímero é uma palavra de origem grega em que polys significa muitos e meros significa partes, podem ser classificados como macromoléculas formadas a partir do encadeamento de moléculas menores, resultando em uma substância grande e de elevado peso molecular. De acordo com as características dos polímeros, os géis podem apresentar natureza iônica ou não-iônica. Os géis de natureza não-iônica possuem estabilidade em ampla faixa de pH, tornando-se possível a veiculação de substâncias de caráter ácido, como os alfahidroxiácidos. Já os de caráter aniônico são pH dependentes, ou seja, apresentam-se estáveis em pH neutro ou próximo do neutro (MAIA CAMPOS et al., 1999).

Segundo fabricantes do Carbopo|ß, o mesmo poderá apresentar resíduos decorrentes do processo de fabricação como o benzeno, entre outros (LUBRIZOL, 2009), sendo o benzeno o responsável por induzir sérios riscos à saúde durante o seu uso.

A escolha de um polímero para a formulação de um gel tem grande influência sobre as características do produto final, como comportamento reológico, estabilidade física do 
produto e sua aceitabilidade pelo consumidor. Na indústria farmacêutica e em produtos cosméticos os polímeros do Carbopol® são utilizados como base dermatológica, veículo que permite incorporação de princípios ativos hidrossolúveis e lipossomas. Muito embora todos proporcionem o espessamento de sistemas hidro alcoólicos, variam entre si em fatores como transparência, aparência visual, economia, facilidade de manuseio e estabilidade.

Os principais compostos utilizados como matéria-prima na preparação de géis são os ácidos carboxivinílicos (Carbopo|ß), os ácidos poliacrílicos (Pemulen®), Carbopo|® Ultrez 10, Carbopol@ 934, Carbopol® 940, Carbopolß ETD 2020 entre muitos outros (CORRÊA et al., 2005).

\subsubsection{Carbopol® 940}

É um polímero obtido pela síntese e polimerização do ácido acrílico. Apresenta- se na forma de pó branco, com odor levemente ácido. Utilizado como agente espessante, e para suspender ingredientes não solúveis e estabilizar emulsões. O Carbopo|® 940 é muito empregado em géis por proporcionar estabilidade em alta e baixas temperaturas, resistência a microrganismos, e estabilidade mesmo em soluções com alto teor de sais, e para conferir transparência ao produto final (SBRT, 2009).

A resina do tipo carbômero 940 é comprovadamente não irritante, seguro, e não oferece meio adequado para crescimento de microrganismos, tais características fazem com que o polímero seja uma escolha segura para o uso em formulações farmacêuticas e em cosméticos (BOAS PRÁTICAS FARMACÊUTICAS, 2015).

O Carbopo|® 940 pode substituir com grande eficiência polímeros naturais, como celulose, gomas, amidos, entre outros, além de polímeros não naturais como PEG, PVP entre outras resinas. No entanto, nenhum desses consegue dar aos géis alcoólicos e hidro alcoólicos a transparência que o Carbopol® 940 produz nesses produtos (SBRT, 2009).

No processo de fabricação do polímero ocorre a presença de resíduos de benzeno, e segundo o fabricante Lubrizol, o carbômero 940 apresenta no seu produto 0,5\% de resíduo de benzeno (LUBRIZOL, 2008).

\subsubsection{Carbopol® 934}

O Carbopo|® 934 é um polímero reticulado de poliacrilato, pó branco, com odor 
ligeiramente ácetico, teor de umidade de 2,0\%, com alta viscosidade, alta estabilidade, com propriedade de fluxo curto em sistema aquoso. Por estas características, e por produzir géis opacos, o seu uso é mais indicado para produção de emulsões, suspensões e cremes (LUBRIZOL, 2008). Segundo o fabricante o polímero apresenta resíduos de benzeno de $0,5 \%$ no produto final (LUBRIZOL, 2008).

\subsubsection{Carbopol@ Ultrez 10}

O polímero Carbopo|® Ultrez 10 é um polímero da família Carbopol® de fácil dispersão que pode ser utilizado em uma variedade de aplicações em produtos de uso pessoal. Diferentemente de alguns aditivos reológicos, este permite uma maior versatilidade na formulação e no processamento, suas propriedades superiores de dispersão fazem do Carbopo|ß Ultrez 10 um aditivo reológico mais fácil de ser processado, economizando tempo valioso de produção (CORRÊA et al., 2005).

Este polímero tem enorme capacidade de umidificação, característica que justifica menor tempo e esforço para atingir uma dispersão sem grumos, pois o Ultrez 10 dispersa bem mais facilmente na água quando comparado ao Carbopol® 940, por exemplo, o qual necessita maior contato com o veículo para dispersar (CORRÊA et al., 2005).

Quando comparado com resinas carbômeras utilizadas no preparo de géis e emulsões, o Carbopo|ß Ultrez 10 desempenha a mesma função de agente espessante, porém com maior eficiência. Sua incorporação aos produtos aquosos e em géis é realizada diretamente (CORRÊA et al., 2005). O Ultrez 10 permite grande versatilidade nas formulações. O polímero umedece rapidamente precisando de menos tempo para formação da dispersão sem grumos, economizando tempo na produção. Ao ser incorporado pode ser utilizado em produtos aquosos ou em gel, sendo possível adicioná-lo diretamente na água (BOAS PRÁTICAS FARMACÊUTICAS, 2015).

As propriedades reológicas do polímero Ultrez 10 são pseudoplásticas e um sistema visco elástico como a maioria destas resinas. Onde ocorre um inchaço gelificado que permite uma maior resistência ao fluxo ou a viscosidade. As suas características físicoquímicas são muito parecidas com o Carbopol® 940 e o Carbopol@ 934, podendo ser considerado híbrido desses dois tipos de resina de Carbopol® (B.F.GOODRICH, 1998).

O Ultrez 10 quando comparado com outros tipos de Carbopol®, como por exemplo - Carbopol® 980, Carbopol® 940, mesmo contendo uma grande semelhança entre os polímeros citados, no espessamento e aplicações de géis e emulsões, em questão de eficiência de espessamento é mais alto que os outros Carbopol®, apresentando até $50 \%$ a 
mais de eficiência em emulsões (GOODRICH, 1998). Além disso o Carbopo|@ Ultrez 10 não apresenta resíduo de benzeno proveniente da produção do polímero, segundo o fabricante Lubrizol (LUBRIZOL, 2007).

O polímero pode ser utilizado em géis e emulsões para que se promova maior transparência no produto em questão, alta viscosidade, maior estabilidade, menor sensação de pegajosidade e fácil armazenamento. Sendo o primeiro Carbopo|® a ser efetivamente disperso sem misturar, e umedece de forma rápida e fácil. No entanto, o Ultrez 10 apresenta algumas limitações no seu uso por sua estrutura deixa-lo vulnerável a substâncias com íons presentes, que são encontrados facilmente em extrato vegetais e umectantes. Por apresentar esta característica, produtos como shampoos, géis de limpeza, géis de banho, géis de $A$. Vera, recomenda-se a utilização de outro tipo de Carbopol® que se comporta melhor na presença de íons, como por exemplo o Carbopolß ETD 2020 (B.F. GOODRICH,1998). Na tabela 1 é possível visualizar as principais diferenças entre os tipos de Carbopo|®.

Tabela 1 - Comparação entre tipos de Carbopo|®

\begin{tabular}{lccc}
\hline \multicolumn{1}{c}{ Polímero } & Ultrez 10 & Carbopol® 934 & Carbopol® 940 \\
\hline Fluidez & Baixa & Baixa & Baixa \\
Viscosidade relativa & Alta & Alta & Muito Alta \\
Capacidade de suspensão & Alta & Alta & Alta \\
Transparência & Alta & Média & Alta \\
Tolerância relativa a íons & Baixa & Baixa & Baixa \\
Tolerância relativa a agitação & Média & Alta & Alta \\
Gel Transparência & Presente & Ausente & Presente \\
Gel hidroalcoólico & Presente & Ausente & Presente \\
Loções & Presente & Presente & Ausente \\
Cremes & Presente & Presente & Presente \\
\hline
\end{tabular}

Fonte: Adaptado de Lubrizol (2007).

\subsubsection{Carbopol® ETD 2020}

Carbopo|® ETD 2020 é um carbômero de fácil dispersão, projetado especialmente para espessar sistemas tensoativos e promover a suspensão de alguns ativos (como por exemplo: Piritionato de Zinco, agente antimicrobiano). É um polímero cruzado do ácido poliacrílico modificado para facilitar seu uso (FAGRON, 2016). 
Processado em um sistema de co-solvente, ele possui uma eficiência de espessamento e uma capacidade de suspensão excelente, garantindo uma transparência brilhante nos sistemas de géis (LUBRIZOL, 2002).

Devido ao bom desempenho em sua dispersão, o Carbopol® ETD 2020 minimiza a formação de grumos, apresentando uma menor viscosidade antes de sua neutralização, facilitando o bombeamento e seu manuseio, durante o processamento em escala produtiva. Uma dispersão de Carbopo|ßB ETD 2020 que contenha polímero em quantidade menor que $2 \%$ por peso, quando não misturado, resulta em uma fase não separada contendo partículas com agregados visíveis. Portanto, recomenda-se que dispersões não neutralizadas e que permaneçam um tempo em repouso, sejam preparadas com no mínimo 2\% em peso de polímero evitando assim a formação de grumos (LUBRIZOL, 2002). Dispersões aquosas concentradas de Carbopol® ETD 2020 são fluídas em níveis de até 4\% de resina de Carbopo|ß em água, pó 100\% ativo (GOODRICH,1998).

O uso do Carbopol® ETD 2020 permite a produção de várias formulações que contenham suspensões permanentes de uma variedade de ingredientes - como exemplo micropartículas de gelatina, princípios anti-caspa insolúveis - em viscosidades pré determinadas em variada concentração de emulsificante (MAPRIC, 2007). Além das características já citadas, outro fator que favorece o seu uso é a ausência de resíduos de benzeno, como afirma o fabricante (LUBRIZOL, 2001).

\subsection{Pemulen® (Emulsificante Polimérico)}

Pemulen® é um emulsionante do tipo óleo em água (o/a), polimérico de ácido poliacrílico predominantemente de alto peso molecular, suas moléculas possuem uma pequena porção com afinidade lipofílica e uma grande porção com afinidade hidrofílica. Proporcionam benefícios para as emulsões como baixa irritabilidade, além de rápida liberação da fase de oleosa (FAGRON, 2007). Produzidos a partir de partículas primárias de polímero com cerca de $0,2 \mu \mathrm{m}$ de diâmetro, cada partícula primária pode ser vista como uma estrutura de rede de cadeias poliméricas interligadas por ligações cruzadas (SHAHIN, 2010). Pemulen® faz parte de uma classe de copolímeros, referido como polímeros transversais ou cruzado de alquil acrilato $\mathrm{C} 10-\mathrm{C} 30$, que é reticulado com um metacrilato de cadeia longa tendo regiões lipofílicas como o metacrilato, bem como regiões hidrofílicas compostos do ácido acrílico (SHAHIN, 2010).

Esse emulsificante polimérico apresenta vários benefícios, podendo estar presente em formulação tópica, oclusiva, promovendo uma boa apresentação do medicamento e 
garantindo baixa irritabilidade à pele, usado em géis tópicos de alta transparência (SHAHIN,2010). Além disso apresenta boa estabilidade da emulsão, liberação rápida da fase oleosa na aplicação da emulsão, simplifica procedimentos de formulação de emulsão, é torna possível a realização de emulsões eficazes com baixas concentrações na fase oleosa, possibilita novas formas de produtos pouco comuns, proporcionando às indústrias elaboração de novos produtos inovadores (GOODRICH, 1998).

Existem dois tipos de Pemulen® o TR1 e TR2, a escolha do polímero a ser utilizado dependerá da viscosidade desejada à formulação ou da quantidade de óleo a ser emulsificada. Os polímeros se diferem pelo poder emulsificante de óleos, quando comparados o Pemulen® TR-2 apresenta maior poder emulsificante que TR-1, porém há uma diminuição da viscosidade do sistema. O Pemulen® TR-1 apresenta viscosidade relativa média, emulsificando até $20 \%$ de óleo enquanto o Pemulen® TR-2 apresenta viscosidade relativa baixa, podendo emulsificar até $50 \%$ de óleo em concentrações usuais, devido a seu caráter mais hidrofóbico (SHAHIN,2010).

Para o preparo de géis o Pemulen® TR-1 é o mais apropriado, e constitui em um veículo ideal para incorporação e dispersão de filtros solares facilitando sua dispersão uniforme e permanência na superfície da pele. É necessário realizar a neutralização na faixa de $\mathrm{pH} \mathrm{4,0} \mathrm{a} \mathrm{8,0} \mathrm{utilizando} \mathrm{trietanolamina,} \mathrm{aminometil} \mathrm{propanol} \mathrm{(AMP-95)} \mathrm{ou} \mathrm{hidróxido}$ de sódio. A concentração usual de Pemulen® TR-1 é de $0,2-0,4 \%$ e de Pemulen® TR-2 de $0,15-0,3 \%$. A tabela 2 traz um comparativo entre diferentes tipos de Carbopol $\Theta$ e o Pemulen®.

Tabela 2 - Tabela comparativa dos carbômeros

\begin{tabular}{cccccc}
\hline Polímero & Aplicações & $\begin{array}{c}\text { Polimerização } \\
\text { solvente }\end{array}$ & $\begin{array}{c}\text { Tipo de } \\
\text { polímero }\end{array}$ & $\begin{array}{c}\text { Densidade } \\
\text { cross-link }^{2}\end{array}$ & $\begin{array}{c}\text { Viscosidade } \\
\text { do gel } \\
\text { aquoso }\end{array}$ \\
\hline Carbopo| ${ }^{\circledR 9} 940$ & Oral/ Tópico & Benzeno & Homopolímero & Alto & Alto \\
ETD 2020 & Tópico & Co-solvente ${ }^{1}$ & Interpolímero & Médio & Médio Alto \\
Ultrez 10 & Tópico & Co-solvente ${ }^{1}$ & Interpolímero & Alto & Muito alto \\
Pemulen® & Tópico & Co-solvente ${ }^{1}$ & Homopolímero & Alto & Médio Alto \\
\hline
\end{tabular}

Nota: ' ${ }^{S}$ istema Co-solvente: ciclohexano e acetato de etila; ${ }^{2}$ Ligações Cruzadas

Fonte: Adaptado de Lubrizol (2010) 


\subsection{Formulações existentes atualmente no mercado}

Foi realizada uma pesquisa no mercado de Pet's, de produtos de higiene oral à base de gel, e constatou-se que a maioria das formulações vendidas atualmente, são semelhantes às citadas abaixo:

- Exemplo 1: Pet Clean®, cada 100g contém:

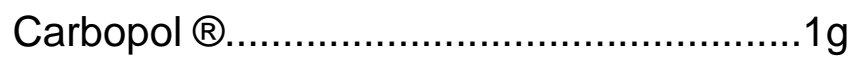

Bicarbonato de Sódio..................................2g

Aromatizante......................................... $0,1 \mathrm{~g}$

Veículo (q.s.p)......................................100g

- Exemplo 2: Dog Clean $\AA$, cada $100 \mathrm{~g}$ contém:

Carbopo|®........................................... $0,35 \mathrm{~g}$

Propilenoglicol...................................... $1 \mathrm{~g}$

Aromatizador de carne .............................. $1 \mathrm{~g}$

Veículo (q.s.p.)........................................100g

- Exemplo 3: Periovet $\AA^{\circledR}$, cada $100 \mathrm{~g}$ contém:

Digluconato de clorexidina......................... $0,12 \mathrm{~g}$

Veículo (q.s.p.)........................................100

Os géis dentais são produtos semi-sólidos que podem abrigar substâncias ativas solubilizadas. Possuem viscosidade variada, que permite a interação de diversas substâncias em suas malhas, entre elas o abrasivo, carbonato de cálcio, que auxilia na remoção da placa bacteriana formada pelo acúmulo de resíduo alimentício no biofilme dentário (MEYER et al., 2007).

\subsection{Proposta de formulação}

Os fitoterápicos, produtos obtidos de matérias primas ativas vegetais, podem estar 
associados à formulação auxiliando na atividade antisséptica e antimicrobiana do gel oral para cães.

- Proposta de uma formulação utilizando fitoterápicos:

Extrato glicólico de Aloe vera.........................................1\%

Extrato glicólico de Mentha piperita................................1\%

Clorexidina................................................................ $0,12 \%$

Glicerina................................................................... 10\%

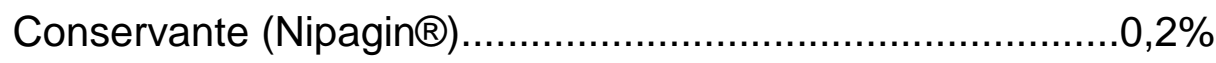

Veículo (q.s.p.).........................................................100

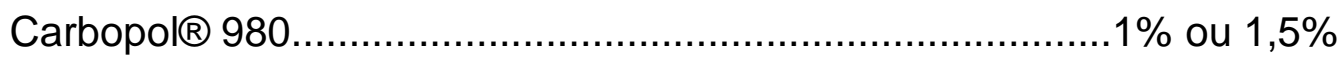

A Hortelã, cujo nome científico é Mentha piperita, da família labiadas e gênero mentha, compreende cerca de 25 espécies um pouco diferentes entre si, mas a maioria bastante conhecida por seu sabor característico e aroma refrescante. Na prática, todas as mentas têm virtudes medicinais semelhantes, as quais se devem essencialmente ao álcool extraído da essência, o mentol, que foi obtido pela primeira vez na Holanda no final do século XVIII. O mentol é um ótimo estimulante estomáquico, um antisséptico, analgésico, com propriedades antiespasmódicas, carminativas, digestivas, além de favorecer a expectoração, aliviar cólicas de origem nervosa, intestinais nefríticas e hepáticas (GUÍMARO, 1983). O mentol, de largo emprego na indústria alimentícia e farmacêutica, é cristalizado com o resfriamento do óleo bruto.

Dentro do gênero Aloe, a mais usada e cultivada é a Aloe vera ( $A$. vera), conhecida como babosa. O significado de Aloe é a substância amarga e brilhante, e vera significa verdadeira. A parte da planta que é utilizada para fins medicinais é a folha. As folhas são suculentas, carnudas de cor verde. $\mathrm{Na}$ epiderme das folhas encontra-se túbulos com a substância mucilaginosa, a qual é denominada um gel de $A$. vera (PARENTE et al., 2013). O uso da $A$. vera é justificado por apresentar algumas atividades biológicas importantes como antioxidante, anti-inflamatória, cicatrizante e antimicrobiana. A atividade antiinflamatória está ligada à inibição da síntese de prostaglandinas e infiltrado, e o efeito cicatrizante está diretamente ligado a manutenção da umidade do local lesionado, que irá estimular a migração de células e proliferação de fibroblastos, havendo a maturação do colágeno de forma mais rápida e com redução de inflamação no local da ferida. Por fim, o 
efeito antimicrobiano está sobre as bactérias gram positivas e negativas (YAO et al., 2009).

A Clorexidina é uma substância sintética antimicrobiana, usada em pequenas concentrações, com efeitos suficientes para inibir a reprodução e/ou exterminar a maioria das bactérias gram-positiva e gram-negativa, leveduras e fungos, que são responsáveis pelo mal hálito do animal (TORTORA et al., 2000). As características químicas da Clorexidina permitem que o produto fique por mais tempo no local aplicado, sendo liberado lentamente e evitando que a saliva do cão neutralize (ROLLA et al., 1975). A substância tem efeito antimicrobiano em tratamentos de gengivites e no tratamento e redução da formação de placa dentária (CURY et al., 2000). Segundo estudiosos, a substância é estável e não tóxica a tecidos, ou absorção pela mucosa ou pele. Não provoca efeitos colaterais ou alteração na microbiota bucal, mesmo com o uso prolongado (ZANATA et al., 2007).

\section{CONSIDERAÇÕES FINAIS}

A maioria das formulações existentes para higiene bucal de cães apresentam em sua formulação o gel de Carbopol®. No entanto, durante a síntese e polimerização de alguns tipos Carbopol® há utilização do benzeno como solvente, o que pode deixar resíduos e provocar graves problemas à saúde. Para o uso contínuo e saudável do gel higienizante bucal dos pet's, concluiu-se que o melhor tipo de Carbopolß para contato com as mucosas e possível deglutição do produto pelo animal, seria o gel de Carbopolß 980, que foi desenvolvido para substituir o Carbopolß 940. Além de oferecer as mesmas propriedades de desempenho, é preferido por ser polimerizado em um sistema co-solvente, ao invés do benzeno.

A utilização do carbômero Ultrez 10 seria de grande interesse por apresentar características de um gel límpido, transparente de alta viscosidade, comporta-se bem com agitação, não apresenta resíduos de benzeno, de fácil manipulação, no entanto não apresenta boa estabilidade com produtos que apresentam íons, como por exemplo extratos, utilizados em nossa proposta de formulação, acarretando problemas futuros ao produto. Uma alternativa seria o uso do ETD 2020, que possui características parecidas com o Ultrez 10, com alta viscosidade, sem teor de benzeno e comportando-se bem em agitação e não apresentado problemas com íons na formulação, sendo estável na presença destes, porém é mais indicado para o uso tópico. Contudo, visando a facilidade de acesso à matéria- 
prima, características físico-químicas, segurança do animal e comportamento diante aos componentes da formulação, foi escolhido o Carbopolß 980.

\section{REFERENCIAS}

ACOFARMA. Ficha Técnica Carbopol. 2009. Disponível em: <http://www.acofarma.com/ admin/uploads/descarga/63883018c63998ab26fcf2dc76e5944cb58881e223d1/main/files /Carbopol\%20y\%20Gel\%20carb\%C3\%B3mero_022302a_PT.pdf>. Acesso em: 03 de maio de 2016.

ATSDR. Toxicological profile for benzene. Atlanta, 2007. Disponível em:< http://www.atsdr.cdc.gov/toxprofiles/tp3.pdf>. Acesso em: 10 de maio de 2016.

BOA PRÁTICAS FARMACÊUTICAS, 2011. Disponível em <http://boaspraticasfarmaceuticas. blogspot.com/2011/11/farmacotecnicos-produtos-e-funcoes-para.html>. Acesso em 16 de abril de 2016.

BRASIL. Ministério da Saúde. Portaria no 776/GM, em 24 de abril de 2004. Dispõe sobre a regulamentação dos procedimentos relativos à vigilância da saúde dos trabalhadores expostos ao benzeno e dá outras providências. Disponível em: <http://portal.saude.gov.br/ portal/arquivos/pdf/Portaria776.pdf>. Acesso em: 10 de maio de 2016.

BRILHO, R. C. Hortelã pimenta. Instituto Agronômico de Campinas. Campinas. 1963. 13p. Disponível em: <http://www.scielo.br/scielo.php?script=sci_nlinks\&ref=000078\&pid=S1516 $-0572201200030000400005 \&$ Ing=pt>. Acesso em: 20 de abril de 2016.

CAMPOS, E.J.; ARAÚJO, R.P.C.; ARAÚJO, M.T.B.; ARAÚJO, D.B.; LIMA, M.J.P.; OLIVEIRA, N.S.; DIAS, A.C. Análise quantitativa da desmineralização do esmalte dental submetido a ação de dentifrícios fluoretados. 2005. Revista de Ciências Médicas Biológicas, Salvador, v. 4, n.3, p. 226-235, set./dez. 2005.

CARAM, RUBENS. Estrutura e Propriedades dos Materiais Poliméricos. Disponível em: <http://www.fem.unicamp.br/ caram/8.\%20MATERIAIS\%20POLIMERICOS\%20GRAD.pdf >. Acesso em: 17 de fevereiro de 2016. 
COLMERY, B.; FROST, R. Periodontal etiology and pathogenesis. Vet Clin North Amer: small anim pract, v.16, n.5, p.817-833, 1986.

CORRÊIA N. M., CAMARGO F. B., IGNÁCIO R. F., LEONARDI G. R., Avaliação do comportamento reológico de diferentes géis hidrofílicos. Curso de Farmácia, Faculdade de Ciências da Saúde, Universidade Metodista de Piracicaba. Revista Brasileira de Ciências Farmacêuticas Brazilian Journal of Pharmaceutical Sciences vol. 41, n. 1, jan./mar., 2005.

CURY, J. A., ROCHA, E.P, KOO, H. et al. Effect of Saccharin on Antibacterial Activity of Chlorhexidine Gel. Braz Dent J. 2000;11(1):29-34 39

DEBOWES, L.J. et al. Association of periodontal disease and histologic lesions in multiple organs from $\mathbf{4 5}$ dogs. J Vet Dent, v.13, n.2, p.57-60, 1996.

DINACO. Importação, Comércio S/A. Ficha de Informações de Segurança de Produtos Químicos; Produto: CARBOPOL 996/20, 2005.

DUPONT, G.A. Understanding dental plaque; biofilm dynamics. J Vet Dent, v.14, n.3, p.91-93, 1997.

DUPONT, G.A. Prevention of periodontal disease. Vet Clin North Amer: small anim pract, v.28, n.5, p.1129-1145, 1998.

EMFAL, FICHA TÉCNICA. 2015. Disponível em <http://www.emfal.com.br/alcool/_Arquivo Produtos/60313.PDF>. Acesso em: 17 de abril de 2016.

ENGLER, A. Syllabus der pfanzenfamilien. Nicoloassen, Berlim, n. 1, v.9, p. 36-38, 1964. Fagron. Informe técnico. Disponível em:<http://cdn.fagron.com.br/doc_prod/docs_3/doc_ 218.pdf> Acesso em 24 de fevereiro de 2016.

FAGRON. Disponível em: <www.fagron.com.br>. Acesso em: 22 de abril de 2016. 
Farmacopeia de Fitoterápicos Brasileira. 1a edição de 2011. Disponível em <http://www.anvisa.gov.br/hotsite/farmacopeiabrasileira/conteudo/Formulario_de_Fitote rapicos_da_Farmacopeia_Brasileira.pdf>. Acesso em 12 de abril de 2016.

Formulário Nacional Da Farmacopeia Brasileira. 2ª edição - Revisão 022012 - FNFB. Disponível em: <http://www.anvisa.gov.br/hotsite/farmacopeiabrasileira/arquivos/2012/FNFB \%202_Revisao_2_COFAR_setembro_2012_atual.pdf>. Acesso em: 13 de março, 2016.

FUNDACENTRO, Efeitos da Exposição ao Benzeno para a Saúde; Série Benzeno. Fascículo 1. 2012. Disponível em <http://www.br.com.br/wps/wcm/connect/b82b51004edd b1e1ae89feab5a03b54d/saude-no-trab-efeitos-benzeno.pdf?MOD=AJPERES>. Acesso em: 10 de maio de 2016.

GARDENQUIMICA; Boletim Técnico; Produto: Carbômero (Acrypol 996); Rev:01-10/13. Disponível em <http://gardenquimica.com.br/boletim/carbomeros.pdf>. Acesso em: 28 de abril de 2016.

GENNARO ALFONSO. A Ciência e a Prática da Farmácia Soluções, Emulsões, Suspensões e Extratos. Pg768 - 770. Ed. gen. Rio de Janeiro, 2014.

GIOSO, M. A.; Odontologia para o clínico de Pequenos Animais. $2^{\underline{a}}$ ed. São Paulo, p.202, 2003.

GUIMARAES, J. C; Rotmeister K.; Nogueira K. C. C; Rodrigues M. F. BENZENO - UFJF. Disponível em <http://www.ufj.br/analiseambiental/files/2011/11/NAGEA-2011-QUIMAMB-JM-BENZENO.pdf>. Acesso em: 05 de maio de 2016.

GUIMARÃES, F. J. R. P. Apostila de riscos químicos. Santos (SP): Senac, 2003.

GUÍMARO, A. L., NUNES, V. A., FUGIXIMA, L. M., HOTOSHI, M., ALMEIDA, C.R., MEINIK, N., PEREIRA, P.C., DIETER, C., DANTAS, S. R., FREY, C. D. Plantas que Curam - A Natureza a Serviço de sua Saúde. ed. TRÊS Livros e Fascículos. São Paulo. 1983

GUO, J. H., 2003. Carbopol® Polymers for Pharmaceutical Drug Delivery Applications. Vol.3, 
n.6. 2003. Disponível em: <http://drug-dev.com/Main/Back-Issues/Carbopol174-Polymersfor-Pharmaceutical-Drug-Deliv-345.aspx>. Acesso em: 18 de abril de 2016.

HANKE, J.; DUTKIEWICZ, T.; PIOTROWSKI, J. The absorption of benzene through human skin. International Journal of Occupational and Environmental Health. Philadelphia, v. 6, n. 2, p. 104-111, Apr./Jun. 2000.

HERBOTECNIA. Tecnologías de cultivo y poscosecha de plantas medicinales, aromáticas y tintóreas. Mentha arvensis. Disponível em: <http://www.herbotecnia.com.ar/exoticamentajaponesa.html>. Acesso em: 5 de dezembro de 2015.

HORTENSE, S. R; CARVALHO, E. S.; CARVALHO, F. S; SILVA, R. P. R.; BASTOS J. R. M.; BASTOS R. S. USO DA CLOREXIDINA COMO AGENTE PREVENTIVO E TERAPÊUTICO NA ODONTOLOGIA. Revista de Odontologia da Universidade Cidade de São Paulo 2010; 22(2): 178-84, mai-ago.

HOSMANI A.H., THORAT Y.S., KASTURE P.V. Carbopol and itsPharmaceutical Significance: A Review. Journal of Microencapsulation.2010. Disponível em: <http://informahealthcare.com/doi/pdf/10.3109/02652040903243445>. Acesso em 15 dezembro de 2015.

LUBRIZOL; Carbomer 934; 2008. Disponível em: <https://www.lubrizol.com/PersonalCare/ Products/Carbopol/Carbopol934.html>. Acesso dia 16 de abril de 2016.

LUBRIZOL, Viscosity of Carbopol $\AA^{*}$ Polymers in Aqueous Systems. November 24, 2009 / January 27, 2010.

LYON, K.F. Dental home care. J Vet Dent, v.8, n.2, p.26- 30, 1991.

LUBRIZOL. Carbopol@ Aqua SF-1 Polymer. Previous Editions: July, 2003 / June, 2006 / July, 2007 / July 19, 2011. Disponível em: <https://www.lubrizol.com/PersonalCare/Products/ Carbopol/CarbopolAquaSF-1.html>. Acesso em : 15 de abril de 2016.

LUBRIZOL. Carbopolß Ultrez 10. 2007. Disponível em: <https://www.lubrizol.com/Personal 
Care/Products/Carbopol/CarbopolUltrez10.html>. Acesso em: 13 de abril de 2016.

LUBRIZOL. CARBOPOL 5984. 2008. Disponível em <https://www.lubrizol.com/Personal Care/Products/Carbopol/Carbopol5984.html> Acesso em: 17 de maio de 2016.

LUBRIZOL. Carbopol Aqua SF-1. 2002. Disponível em <https://www.lubrizol.com/Personal Care/Products/Carbopol/CarbopolAquaSF-1.html> Acesso em 17 de maio de 2016.

MAPRIC. Disponível em: <http://www.mapric.com.br/anexos/boletim307_23082007_163519. pdf>. Acesso em: 15 de março de 2016.

MEYER, A. C. A.; TERA, T. M.; ETO, Y. Manual Odontológico de Formulações Manipuladas. Livraria Santos Editora Ltda., 2007, São Paulo, p.6-8.

MILLER, B.R.; HARVEY, C.E. Compliance with Oral Hygiene Recommendations Following Periodontal Treatment in Clientowned Dogs. J Vet Dent, v.11, n.1, p.18-19, 1994.

MOSTAFA, S., SEHAM, A. H. Optimized formulation for topical administration of clotrimazole using Pemulen polymeric emulsifier. Drug Development and Industrial Pharmacy . 37(5):559-68. Dez. 2010.

PASSOS, I. A., MASSONI, A. C. L. T., FERREIRA, J. M. S., FORTE F. D. S., SAMPAIO F. C. Evaluation of physical conditions and storange of toothbrushes in day cares of João Pessoa - Paraíba, Brasil. Rev Odontol UNESP.2006; 35(4): 299-303.

PARENTE, L.M.L., CARNEIRO, L.M., TRESVENOL, L.M.F., GARDIN, N.E. Aloe vera: Botanical, Phytochemical and Therapeutic Characteristics. Arte Médica Ampliada Vol. 33 | N. 4 | Outubro / Novembro / Dezembro de 2013.

PENMAN, S.; Dental conditions in the dog and cat. Veterinary Ann. p.223-232, 1990.

PENNMAN, S., HARVEY, C.E. Periodontal Disease. (2 ${ }^{\mathrm{a}}$ edição). Manual of Small Animal dentistry (pp.37-48). West Sussex: KCO.1992.

RÖLLA, G., MELSEN, B. On the Mechanism of the Plaque Inhibition by Chlorhexidine. 
J Dent Res.;54 Spec No B:B57-62. 1975.

SBRT - Serviço Brasileiro de Respostas Técnicas. Respostas Técnicas. Disponível em: <http://sbrt.ibict.br/acessoRT/4945>. Acesso em: 28/01/2016.

SBRT. Serviço Brasileiro de Respostas Técnicas. Resposta Técnica. 2009. Disponível em: < http://www.sbrt.ibict.br>. Acesso em: 21 de novembro de 2015.

SILVERSON, MACHINES. Disponível em: <http: //www.silverson.com>. Acesso em: 24 de abril de 2016.

TORTORA, G.J., FUNKE, B.R, CASE, C.L. Controle do Crescimento Microbiano. In: Tortora GJ, Funke BR, Case CL. Microbiologia. 6 ed. Porto Alegre: Artmed,. P.181-206. 2000.

YAO, H., CHEN, Y., LI, S., HUANG, L., CHEN, W., LIN, X. Promotion Proliferation Effect of a Polysaccharide from Aloe barbadensis Miller on Human Fibroblasts in vitro. Int $\mathrm{J}$ Biol Macromol. 45(2):152-6. 2009. 43

ZANATA, F. B, ROSING, C. K; CHLORHEXIDINE: ACTION'S MECHANISMS AND RECENT EVIDENCES OF IT'S EFFICACY OVER SUPRAGINGIVAL BIOFILM CONTEXT. Scientific-A;1(2):35-43; 2007. 